\title{
A EQUIPE DE SAÚDE DA FAMÍLIA E O PORTADOR DE TRANSTORNO MENTAL: RELATO DE UMA EXPERIÊNCIA
}

Marjorie Ester Maciel ${ }^{1}$

RESUMO: Este trabalho é o relato de uma experiência da equipe de Saúde da Família do município de Vicentina-MS, que tem como objetivo relatar a contribuição da equipe de saúde da família na promoção da saúde mental através da reintegração sócio-familiar do portador de transtorno mental. Constatou-se que, ao prestar assistência a um paciente portador de transtornos mentais, houve a superação do medo e do preconceito da equipe em relação ao paciente. Assim, espera-se com este trabalho contribuir diretamente para o incremento das ações de saúde mental na ESF e, secundariamente, para a mudança de modelo da assistência em saúde mental no Brasil e na consolidação dos pressupostos da Reforma Psiquiátrica. PALAVRAS-CHAVE: Saúde mental; Saúde da família; Estigmatização.

\section{FAMILY HEALTH TEAM AND THE MENTAL PATIENT: AN EXPERIENCE ACCOUNT}

\begin{abstract}
This paper is an experience account of the family health team from the municipality of Vicentina-Mato Grosso do Sul State/Brazil. It objectifies to point out the team's contribution to promote mental health through sociofamily integration of the mental patient. It was evidenced that, by delivering care to a mental patient, fear and prejudice were overcome by the team in relation to the patient. Thus, it is expected to contribute directly for the increment of mental health actions in Family Health Teams and consequently for the change of the mental health care delivery model in Brazil, and the consolidation of the Psychiatric Reform assumptions.
\end{abstract}

KEYWORDS: Mental health; Family Health; Prejudice.

\section{EL EQUIPO DE SALUD DE LA FAMILIA Y EL PORTADOR DE TRASTORNO MENTAL: INFORME DE UNA EXPERIENCIA}

RESUMEN: Este trabajo es el relato de una experiencia del equipo de salud de la familia del municipio de Vicentina-MS. Cuando se dio asistencia a un paciente portador de trastornos mentales, hubo la superación del prejuicio del equipo en relación al paciente. El objetivo de este artículo es contribuir directamente para lo incremento de las acciones de salud mental en la ESF y secundariamente para la consolidação del cambio de modelo de la asistencia en salud mental en Brasil y en la consolidação de los presupuestos de la Reforma psiquíatrica.

PALABRAS CLAVE: Salud mental; Salud de la familia; Estigmatización. 


\section{INTRODUÇÃO}

O Programa Saúde da Família (PSF) surgiu no Brasil em 1994, após experiências bem sucedidas com Agentes Comunitários de Saúde (ACS) na redução da mortalidade infantil no interior da região Nordestina. Tem como alicerce o trabalho multiprofissional e interdisciplinar de uma equipe voltado para uma clientela adstrita. A princípio o PSF seria mais um programa do Ministério da Saúde, todavia por sua capacidade de reorganizar o sistema, através da promoção da saúde e dos princípios do SUS essa denominação tornou-se inadequada para a saúde da família ${ }^{(1)}$. Assim, pelo espaço político e institucional ocupado, a saúde da família transforma-se em estratégia reestruturante da Atenção Básica ${ }^{(1-2)}$. Então, a partir de 1997, a saúde da família passa a ser denominada e defendida como estratégia( ${ }^{(3)}$, fundamentada em uma prática interdisciplinar de diversos profissionais da área da saúde e de áreas afins $^{(4)}$.

A Estratégia da Saúde da Família (ESF) possui como equipe mínima: um médico, um enfermeiro, um a dois auxiliares de enfermagem e de seis até 12 ACS, que devem conforme preconizado abordar o indivíduo dentro de seu contexto familiar e comunitário. Tais abordagens visam contemplar todas as fases de vida do ser humano e têm um caráter de integralidade; isto significa que 0 atendimento prestado pelos profissionais da ESF deve abranger não só o aspecto biológico, mas também psicossocial do ser humano, realizando assistência centrada na pessoa ao invés da sua doença. Desse modo, subentende-se que a saúde mental é área de importante atuação da equipe de saúde da família.

Nesse contexto, muitas vezes ao observar o cotidiano de trabalho das equipes de saúde da família, constato que, na maior parte do tempo, a promoção da saúde mental fica em segundo plano diante das outras ações de saúde que são desenvolvidas pelas equipes em que há necessidade de envio de relatórios, tais como: acompanhamento de hipertensos, diabéticos, gestantes, entre outras. Isso corrobora com Scóz e Fenili ${ }^{(5)}$ que referem que existe ESFs em que verificase a total inexistência de ações em saúde mental .

Esse fato se deve porque talvez o profissional de saúde não esteja preparado para atuar na promoção da saúde mental, e pela dificuldade em superar o estigma historicamente determinado que envolve os portadores de transtornos mentais no qual permeia a idéia de que eles sejam perigosos, inconvenientes e incapazes de viver em sociedade ${ }^{(6)}$. Quanto ao despreparo, ele está relacionado à formação acadêmica do profissional de saúde cuja ênfase é dada ao raciocínio lógico e clínico desvalorizando a abordagem simbólica e o subjetivismo ${ }^{(7)}$.

Por outro lado, com o surgimento da Reforma Psiquiátrica cabe aos profissionais de saúde consolidar os preceitos desta. Dentre os quais se cita a desinstitucionalização do portador de transtornos mentais e a sua reintegração no convívio familiar e social, pois tratar o indivíduo isoladamente de sua família não se alcança efetividade, portanto, qualquer ação de saúde mental ou tratamento devem ser planejados dentro do contexto familiar ${ }^{(8)}$.

Assim, este artigo tem por objetivo relatar uma experiência destacando a contribuição da equipe de saúde da família na promoção da saúde mental, através da reintegração sócio-familiar do portador de transtorno mental.

\section{DESCRIÇÃO DO LOCAL}

Essa experiência deu-se na atuação como enfermeira de uma equipe de saúde da família no município de Vicentina, localizado no interior do Mato Grosso do Sul, com população estimada em 5.627 mil habitantes segundo o IBGE ${ }^{(9)}$.

O referido município possui $100 \%$ de cobertura pela Estratégia Saúde da Família, com a atuação de duas ESF. A economia local baseia-se na cultura da soja e do milho. Os principais problemas de saúde da população são: gravidez na adolescência, alcoolismo, transtorno de ansiedade, depressão, hipertensão e diabetes.

Respeitou-se os aspectos éticos de sigilo e anonimato do sujeito de acordo com a resolução n.196/ 96 do Conselho Nacional de Pesquisa.

O caso aqui descrito foi selecionado por ter sido o primeiro vivenciado na trajetória profissional como enfermeira da estratégia da família.

\section{RELATO DA EXPERIÊNCIA}

A primeira situação vivenciada na equipe da ESF de Vicentina foi com o senhor J.S. casado, 45 anos, diagnóstico de esquizofrenia que após agressão física a uma pessoa em momento de surto psicótico, foi preso e encaminhado para internação em um hospital psiquiátrico de referência na região. Ao receber alta hospitalar o referido paciente veio residir na área de 
cobertura da ESF na qual atuo. Isso aconteceu devido à vergonha da família perante os antigos vizinhos. No entanto, logo corria na nova vizinhança o boato sobre o acontecido.

A equipe recebeu um ofício da Promotoria Pública com a solicitação de acompanhamento semanal do comportamento do paciente. Esse ofício despertou na equipe ansiedade e medo em relação a essa situação, deixando evidente a limitação para assistir o portador de doença mental, confirmando a constatação $^{(6)}$ de que o profissional de saúde tem dificuldade de superar estigmas relacionados às doenças mentais. Havia o medo de que ele pudesse nos agredir fisicamente durante a visita domiciliar.

Justamente por esse temor procurou-se primeiramente a esposa de J.S., em seu local de trabalho, a senhora A.L. de 42 anos. Nesse encontro ela foi informada de que a equipe realizaria visita domiciliar ao seu cônjuge com o objetivo de colaborar com reabilitação dele. No entanto, o real motivo que era o cumprimento de uma solicitação legal, foi omitido.

Percebeu-se desconfiança e vergonha por parte de A.L. em relação à visita e aos questionamentos realizados, e ela aparentava ter receio de que seu esposo pudesse ser prejudicado por nós de alguma forma. Mesmo assim, a senhora A.L. aceitou que o acompanhamento fosse realizado. Durante essa conversa questionamos sobre o padrão de comportamento que seu esposo estava mantendo no momento e ela relatou que seu marido estava "tranqüilo" e fazendo o uso correto das medicações que foram prescritas durante a alta hospitalar.

A obtenção dessas informações deixou a equipe mais tranqüila para realizar a visita que foi agendada com a esposa do senhor J.S. em um horário no qual ela estivesse presente, já que na casa moravam somente os dois. Foi solicitado à senhora A.L. que preparasse seu marido para nossa visita, informando que o intuito da mesma era conhecer a nova família residente na área de abrangência da unidade de saúde da família, pois tínhamos receio de que se ele soubesse o real motivo da visita isso o faria comportar-se de forma hostil conosco.

No dia e hora determinado comparecemos ao domicílio da senhora A.L. e J.S. e fomos recebidos pela senhora A.L. e nos acomodamos em um banco embaixo de uma árvore no quintal. Achamos mais seguro não entrar na residência, pois nossos medos ainda estavam muito presentes.

Decorridos alguns instantes, o senhor J.S. apareceu e sentou-se conosco. Estava com uma aparência boa e uma feição serena. Conversamos sobre vários assuntos, até mesmo sobre a colheita da soja e a horta que ele tinha em seu quintal. Com o passar dos minutos começamos a ficar mais à vontade e a tensão foi desaparecendo. Depois de discutirmos esses assuntos percebemos que J.S. sentiu-se mais confortável com a nossa presença e ele próprio tomou a iniciativa de falar a respeito de sua saúde.

Primeiramente, contou-nos que fazia tratamento de saúde, porém sem especificar qual seria a sua enfermidade e que seu médico havia lhe recomendado que não tomasse sol e nem realizasse tarefas que demandasse muito esforço físico. Para encerrar, relatou-nos também que está "encostado pelo INSS" por causa de seu problema de saúde.

Procurando saber mais sobre seu estado de saúde, indagamos sobre uso diário de alguma medicação. Após um momento de silêncio disse que usava "remédio controlado", contou-nos o modo de uso e horários e começou a falar de sua internação, do "acesso" e de como esse acontecimento lhe rendeu "problemas com a justiça”. Mas, a surpresa veio mesmo, quando ele mencionou que sabia o motivo da nossa visita, que "era para cumprir ordem do juiz", pois ele havia sido avisado no fórum que esse fato iria acontecer. Como o subestimamos! Durante as visitas subseqüentes o paciente manteve seu comportamento inalterado. Porém, o comportamento da equipe modificou-se, perdemos todo o receio de aproximarmos dele e foi iniciada ação de integração do paciente no seu meio social.

Incentivamos o paciente a freqüentar as atividades de educação em saúde oferecidas pela ESF e as reuniões dos programas sociais do qual participava. A nova vizinhança antes receosa começou a mudar seus conceitos, após ver a presença constante da equipe da ESF no domicílio de J.S. e observar que as visitas transcorriam de forma tranqüila. Com a freqüência de J.S. nos grupos foram criados laços de amizade. Importante destacar que J.S. estava cumprindo corretamente as prescrições medicamentosas e que estava orientado auto e alopsiquicamente.

Após essa primeira e bem sucedida experiência com portador de transtorno mental, com o medo e o estigma diminuídos, foi possível atuar de forma mais intensa, com um olhar diferenciado facilitando uma assistência integral e inclusiva destes nossos clientes.

Essa experiência possibilitou um aprendizado a 
toda equipe, que a partir dessa vivência começou a "enxergar" o portador de transtorno mental, tirando-o da sua invisibilidade e passou-se a desenvolver um trabalho na comunidade buscando a obtenção da redução de internação destes e na busca pelo fim da estigmatização das enfermidades mentais e de seus portadores.

\section{CONSIDERAÇÕES FINAIS}

Os profissionais de saúde também estigmatizam o doente mental. Essa estigmatização, que é de base histórica, precisa ser trabalhada e discutida com a equipe e a comunidade, objetivando a inserção social do portador de doença mental, para que seja aceito e acolhido com e apesar de suas limitações.

O compartilhamento dessa experiência pode contribuir diretamente para o incremento das ações de saúde mental na ESF e secundariamente para a mudança de modelo da assistência em saúde mental no Brasil e na consolidação dos pressupostos da Reforma Psiquiátrica entre os quais destaca-se a ênfase na atenção integral, na reabilitação psicossocial e no entendimento do processo saúde-doença mental relacionado à qualidade de vida ${ }^{(10)}$, resultando na melhoria da qualidade da assistência mental e na redução da estigmatização do portador de transtorno mental.

\section{REFERÊNCIAS}

1. Souza HM. Reforma da reforma. Rev Bras Saúde Fam. 2002;2(4):2-3.

2. Tomaz JBC. O agente comunitário de saúde não deve ser um “super-herói”. Interface. 2003;6(10):84-7.

3. Ribeiro EM. As várias abordagens da família no cenário do programa. Rev Latino-Am Enferm. 2004;2(4):658-64.

4. Sousa KKB, Filha MOF, Silva ATMC. A práxis do enfermeiro no programa de saúde da família na atenção à saúde mental. Cogitare Enferm. 2004 Jul/Dez;9(2):14-22 .

5. Scóz TMX, Fenili RM. Como desenvolver projetos de atenção à saúde mental no programa de saúde da família. Rev Eletrôn Enferm. 2003;5(2):71-7.

6. Silveira LC, Braga VAB. Acerca do conceito de loucura e seus reflexos na assistência de saúde mental. Rev Latino-Am Enferm. 2005;13(4):591-5.

7. Benetton LG. Temas em psicologia da saúde: a relação profissional-paciente. Campinas (SP): Unicamp; 2002.

8. Oliveira MAF, Colvero LA.A saúde mental no programa saúde da família. Disponível em: www.ids-saude.org.br/ enfermagem>. Acesso em 16 Dez 2007.

9. Instituto Brasileiro de Geografia e Estatística - IBGE. Contagem populacional. Disponível em: <http// www.ibge.gov.br/cidades>. Acesso em 16 Fev 2007.

10. Ministério da Saúde (BR). Relatório Final da $2^{\circ}$ Conferência Nacional de Saúde Mental.Brasília (DF): Ministério da Saúde, 1994.

Cogitare Enferm 2008 Jul/Set; 13(3):453-6 